\title{
Anti-aging effect of fullerenol on skin aging through derived stem cells in a mouse model
}

\author{
WEI LI, NING LI, BING SUI and DAPING YANG \\ Department of Plastic Surgery, The Second Affiliated Hospital of \\ Harbin Medical University, Harbin, Heilongjiang 150081, P.R. China
}

Received January 29, 2016; Accepted February 14, 2017

DOI: $10.3892 /$ etm.2017.5163

\begin{abstract}
Fullerenol is similar to graphite in terms of structure. In the present study, the anti-aging effect of fullerenol on skin through derived stem cells in a mouse model was assessed and the potential mechanism of fullerenol was investigated. The anti-aging effect of fullerenol effectively inhibited the retention rate of transplanted adipose-derived stem cells and increased the thickness of the dermal portion of skin and collagen ratio in mice. The effect of fullerenol on the proliferation of stem cells was observed. Treatment with fullerenol effectively promoted the mRNA expression of Runt-related transcription factor 2, alkaline phosphatase and osteocalcin in a mouse model of skin aging induced by D-galactose. However, fullerenol treatment effectively suppressed the protein expression of peroxisome proliferator-activated receptor- $\gamma$ (PPAR- $\gamma$ ) and increased forkhead box protein $\mathrm{O} 1$ (FoxO1) protein expression in the mice model of skin aging induced by D-galactose. These results demonstrate that the anti-aging effect of fullerenol on skin through derived stem cells may be mediated in mice via the PPAR- $\gamma /$ FoxO1 signaling pathway.
\end{abstract}

\section{Introduction}

Skin aging, which affects physical appearance and leads to skin diseases, can be due to an interaction of multiple factors, such as inflammation and trauma, nephropathy, hepatopathy (1). At present, there are a number of therapeutic options, including surgical and chemical peel methods, to treat skin aging (1). However, securer and more dependable potential treatments should be investigated as current means have insignificant curative effects, numerous adverse reactions and poor patient compliance (2).

Correspondence to: Dr Daping Yang, Department of Plastic Surgery, The Second Affiliated Hospital of Harbin Medical University, 246 Xuefu Road, Harbin, Heilongjiang 150081, P.R. China

E-mail: yangdaping@aliyun.com

Key words: fullerenol, skin aging, stem cells, peroxisome proliferator-activated receptor- $\gamma$, forkhead box protein $\mathrm{O} 1$
Adipose-derived stem cells (ADSCs) are isolated and purified from subcutaneous fatty tissues, possess a self-renewing ability and multiple differentiation potentials and may secrete biologically active factors to repair damaged organ tissues including cardiac muscle, nerves, kidney and arthrodial cartilage (3). Anti-aging functions of ADSCs have been preliminarily supported by a previous study (4).

Fullerenol is a generic term for a hollow spheroidal, ellipsoid-shaped, columnar order and tracheary molecule formed completely by carbon (5). It is also the fourth allotropic substance of carbon identified following adamas, graphite and amorphous carbon (6). Fullerenol is a water-soluble fullerene derivative, and has previously been demonstrated to be a powerful antioxidant (6). For a number of neurodegenerative diseases, glutamic acid receptors are excessively activated, resulting in large production of nitric oxide free radicals and reactive oxygen species (7). In primary cultured mouse neurons, fullerenol possesses good oxidation resistance, which may inhibit the apoptotic process of neuronal excitability caused by oxidative stress (8). Every fullerenol may absorb a number of oxygen free radicals to decrease the damage effects of oxygen free radicals on nerve tissues (6). Furthermore, fullerenol may interdict functions of glutamic acid receptors to further prevent neurons from apoptosis (9). The aim of the present study was to use a mouse model of skin aging induced by D-galactose to analyze the anti-aging effects of fullerenol on skin aging through derived stem cells.

\section{Materials and methods}

Isolation and culture of ADSCs. A total of 24 male green fluorescent protein-expressing mice (6-week-old; 20-22 g) were obtained from the Animal Center of Harbin Medical University (Harbin, China). Mice were housed at $22-24^{\circ} \mathrm{C}$ and $55-60 \%$ humidity with a $12 \mathrm{~h}$ light/dark cycle with free access to food and water. Mice were sacrificed via decapitation under anesthesia (35 mg/kg pentobarbital; Sigma-Aldrich, Merck KGaA, Darmstadt, Germany) following sacrifice, the skin was incised and inguinal fat pad adipose tissue samples were separated and washed with PBS, which were sliced into sections $(5-10 \mathrm{~mm})$ and digested with $0.15 \%$ type I collagenase for $30 \mathrm{~min}$ at room temperature. The supernatant was separated from pellets by centrifugation at $1,500 \mathrm{x} g$ and the pellets were resuspended with phosphate-buffered saline (PBS). The 
Table I. Primer sequences of Runx2, ALP and OCN.

\begin{tabular}{lll}
\hline Molecule & \multicolumn{1}{c}{ Sense } & \multicolumn{1}{c}{ Antisense } \\
\hline Runx2 & 5'-AGATGATGACACTGCCACCTCTG-3' & 5'-GGGATGAAATGCTTGGGAACTGC-3' \\
ALP & 5'-ACCATTCCCACGTCTTCACATTTG-3' & 5'-AGACATTCTCTCGTTCACCGCC-3' \\
OCN & 5'-CAGCGAGGTAGTGAAGAGAC-3' & 5'-TGAAAGCCGATGTGGTCAG-3' \\
GAPDH & 5'-ATGGCATCAAGAAGGTGGTG-3' & 5'-CATACCAGGAAAATGAGCTTG-3'
\end{tabular}

Runx2, Runt-related transcription factor 2; ALP, alkaline phosphatase; OCN, osteocalcin.

solution was then filtered with a $200 \mathrm{~mm}$ mesh into spin down stromal-vascular fraction cell pellets. The retrieved cell fraction was cultured in Dulbecco's modified Eagle's medium (Gibco; Thermo Fisher Scientific, Inc., Waltham, MA, USA), $10 \%$ fetal bovine serum (Gibco; Thermo Fisher Scientific, Inc.), $100 \mathrm{U} / \mathrm{ml}$ penicillin and $100 \mathrm{mg} / \mathrm{ml}$ streptomycin (both from Sigma-Aldrich; Merck $\mathrm{KGaA}$ ) at $37^{\circ} \mathrm{C}$ with $5 \% \mathrm{CO}_{2}$ for 3 weeks. Animal experimental protocols were approved by the Second Affiliated Hospital of Harbin Medical University Heilongjiang Laboratory Animal Administration Committee (Harbin, China) and experiments were in accordance with the Institutional Guidelines for Animal Experimentation.

D-galactose-induced aging model and animal experiments. A total of 30 male 6-week-old nude mice (20-22 g) were provided by the Harbin Medical University Heilongjiang Experimental Animal Center. Mice were housed and 22-24 ${ }^{\circ} \mathrm{C}, 55-60 \%$ humidity with access to food and water ad libitum. Mice were randomly divided into three groups $(\mathrm{n}=10$ in each group): Control, model and fullerenol groups. The model and fullerenol groups of mice were administered $1,000 \mathrm{mg} / \mathrm{kg}$ D-galactose (Sigma-Aldrich; Merck KGaA) by subcutaneous injection. Following 2 weeks of acclimation, the control and model groups were administered PBS by subcutaneous injection. The fullerenol group mice were administered a subcutaneous injection of $10^{6}$ GFP-expressing ADSCs and $100 \mathrm{mg} / \mathrm{kg}$ fullerenol (Sigma-Aldrich; Merck KGaA), as previously described (10). Following 3 weeks of treatment, mice were sacrificed by decapitation under $30 \mathrm{mg} / \mathrm{kg}$ of pentobarbital. Skin was immediately harvested washed and stored at $-80^{\circ} \mathrm{C}$.

Differentiation of mice ADSC. ADSCs were divided into two groups: Control and fullerenol. In the control group, ADSCs were induced with $\beta$-glycerophosphate and $10^{-7} \mathrm{M}$ dexamethasone; in the fullerenol group, ADSCs were induced using $10 \mathrm{mM} \beta$-glycerophosphate and $10^{-7} \mathrm{M}$ dexamethasone in medium supplemented with $100 \mu \mathrm{M}$ fullerenol for 3 weeks. All ADSCs were stained using Oil-Red O staining, which identifies fat, bone and cartilage cells. Differentiation of ADSCs was observed using a BX51 light microscope (Olympus, Tokyo, Japan).

Differentiation of retention rate and thickness of the dermal portion of skin. Skin tissue samples were fixed in $4 \%$ paraformaldehyde at room temperature for $24 \mathrm{~h}$, dehydrated and paraffin-embedded. Then, hematoxylin and eosin was used to stain skin tissue samples, which were extracted from the cell injection site of the mice at the midline of the dorsum. Skin tissue samples were cut into 6-mm sections and assessed under a BX51 light microscope and imaged using a DP71 digital camera (both from Olympus). The total collagen content was analyzed with the aniline blue staining, which was observed using Image J software version 3.0 (National Institutes of Health, Bethesda, MD, USA).

Lactate dehydrogenase ( $L D H)$ and cell viability assay using MTT. A total of $2-3 \times 10^{3}$ ADSC were seeded into 96-well plates and cultured with $0.1,0.3,1$ or $3 \mu \mathrm{M}$ fullerenol for $24 \mathrm{~h}$ at $37^{\circ} \mathrm{C}$. Cytotoxicity was assessed using $1 \%$ Triton X-100 and a detergent leading to a complete release of the LDH enzyme (Sigma-Aldrich; Merck KGaA). To assess cell viability, $100 \mu \mathrm{l}$ sterile MTT dye $(0.5 \mathrm{mg} / \mathrm{ml}$; Sigma-Aldrich; Merck KGaA) was incubated with the ADSCs for $4 \mathrm{~h}$ at $37^{\circ} \mathrm{C}$ and $150 \mu \mathrm{l}$ dimethyl sulfoxide for $15 \mathrm{~min}$. Cytotoxicity and cell viability were measured at $490 \mathrm{~nm}$ using a microplate ELISA reader (Bio-Rad Laboratories, Inc., Hercules, CA, USA).

Reverse transcription-quantitative polymerase chain reaction (RT-qPCR) of Runt-related transcription factor 2 (Runx2), alkaline phosphatase (ALP) and osteocalcin (OCN). Mice were sacrificed and skin tissue was immediately collected and stored at $-80^{\circ} \mathrm{C}$. Total ribonucleic acid (RNA) was isolated from skin tissue samples using the RNeasy ${ }^{\circledR}$ Mini kit in accordance with the manufacturer's instructions (Qiagen, Valencia, CA, USA). Using the Reverse Transcription System kit in accordance with the manufacturer's instructions (Promega Corporation, Madison, WI, USA), $1 \mu \mathrm{g}$ total RNA was reverse transcribed into cDNA. The gene expression of Runx2, ALP and OCN were measured using Real-time PCR with the QuantiTect ${ }^{\circledR}$ SYBR Green PCR master mix in accordance with the manufacturer's instructions (Qiagen). The primer sequences and product sizes are presented in Table I. GAPDH was used as a reference gene. The PCR amplification was initiated at $94^{\circ} \mathrm{C}$ for $3 \mathrm{~min}$, followed by 40 cycles of $95^{\circ} \mathrm{C}$ for $35 \mathrm{sec}, 60^{\circ} \mathrm{C}$ for $45 \mathrm{sec}, 72^{\circ} \mathrm{C}$ for $30 \mathrm{sec}$ and a final step at $72^{\circ} \mathrm{C}$ for $5 \mathrm{sec}$. The experiment was repeated three times.

Western blot analysis. Skin tissue samples were homogenized in an ice-cold lysis buffer and total protein levels were quantified using a BCA protein assay kit (both from Beyotime Institute of Biotechnology, Haimen, China). For each sample, $50 \mu \mathrm{g}$ total protein was run on 10-12\% SDS-PAGE and electro-transferred to nitrocellulose membranes (Thermo Fisher Scientific, Inc.). The membranes were blocked using Tris-buffered saline 


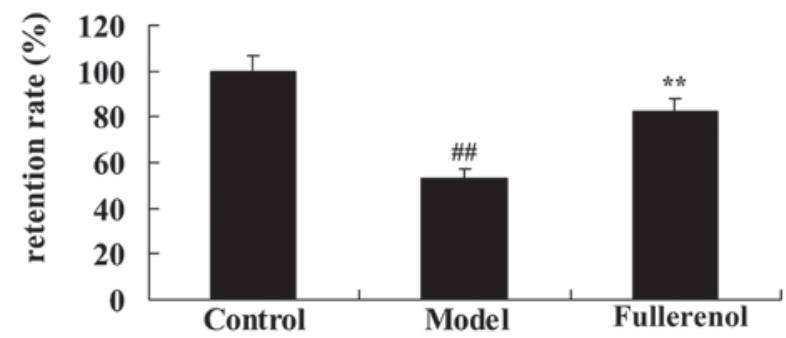

Figure 1. Effect of fullerenol on adipose differentiation of adipose-derived stem cells. ${ }^{\# \#} \mathrm{P}<0.01$ vs. control group; ${ }^{* *} \mathrm{P}<0.01$ vs. model group. Control, control group; fullerenol, $100 \mathrm{mg} / \mathrm{kg}$ fullerenol treated group.
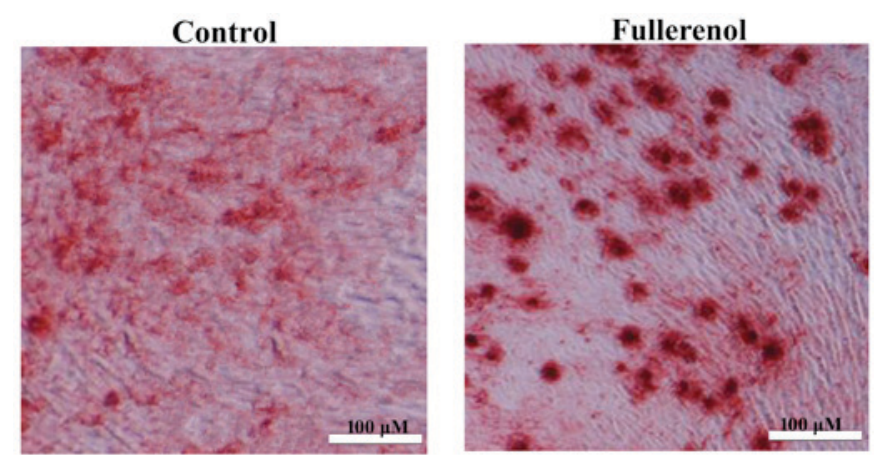

Figure 2. Effect of fullerenol on the retention rate of transplanted adipose-derived stem cells. Stained with Oil-Red O and imaged with a microscope (magnification, x40). Control, control group; model, D-galactose-induced model mice; fullerenol, $10^{6} \mathrm{GFP}$-expressing adipose-derived stem cells and $100 \mathrm{mg} / \mathrm{kg}$ fullerenol treated group.

and Tween-20 (50 mM Tris, $\mathrm{pH}$ 7.6, $150 \mathrm{mM} \mathrm{NaCl}, 0.05 \%$ Tween-20) with 5\% bovine serum albumin (Shanghai Sangong Pharmaceutical Co., Ltd., Shanghai, China) for $1 \mathrm{~h}$ at room temperature. The membranes were washed with TBST, and incubated with anti-peroxisome proliferator-activated receptor- $\gamma$ (PPAR- $\gamma$, sc-9000; Santa Cruz Biotechnology Inc., Dallas, TX, USA), anti- forkhead box protein O1 (FoxO1, ab52857; Abcam, Cambridge, UK) and $\beta$-actin (Santa Cruz Biotechnology, Inc.) overnight at $4^{\circ} \mathrm{C}$. The membranes were incubated with anti-rabbit horseradish peroxidase-conjugated secondary antibody (A0208, 1:2,000; Beyotime Institute of Biotechnology) for $1 \mathrm{~h}$ at room temperature followed by incubation at $37^{\circ} \mathrm{C}$ for $1 \mathrm{~h}$ with chemiluminescent substrate for horseradish peroxidase antibody and enhancer solution (Thermo Fisher Scientific, Inc.). Protein blank was analyzed by Quantity One software 3.0 (Bio-Rad Laboratories, Inc.). Three replicates were performed.

Statistical analysis. The results of the quantitative and morphometric analyses were calculated as the mean \pm standard error of the mean by SPSS 17.0 (SPSS, Inc., Chicago, IL, USA). Statistical analysis was conducted using one-way analysis of variance followed by Dunnett's test. $\mathrm{P}<0.05$ was considered to indicate a statistically significant difference.

\section{Results}

Effect of fullerenol on adipose differentiation of ADSCs. ADSCs induced by fullerenol following 3 weeks were observed using a microscope. There was a significant inhibition of

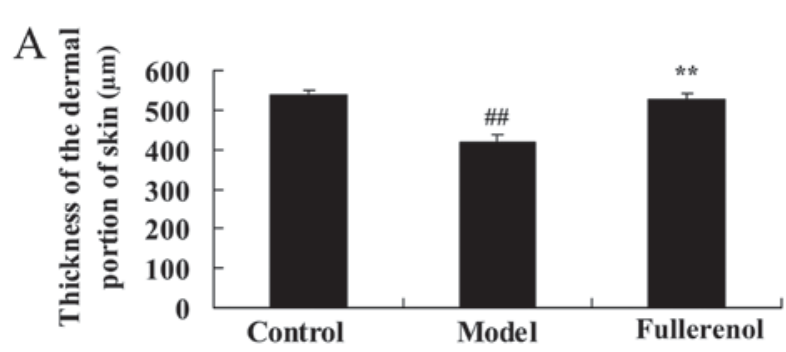

B

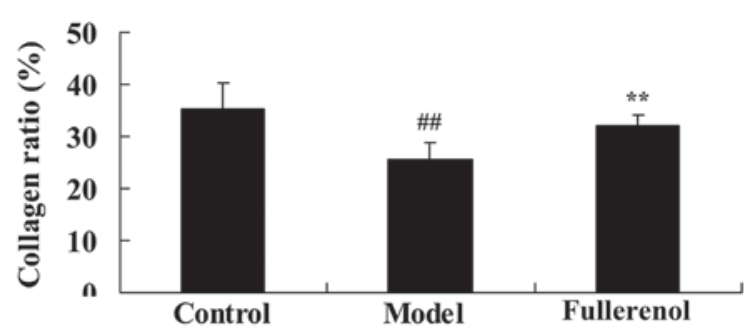

Figure 3. Effect of fullerenol on the thickness of the dermal portion of skin and collagen ratio. Anti-aging effect of fullerenol on (A) the thickness of the dermal portion of skin and (B) collagen ratio. ${ }^{\# \#} \mathrm{P}<0.01$ vs. control group; ${ }^{* *} \mathrm{P}<0.01$ vs. model group. Control, control group; model, $\mathrm{D}$-galactose-induced model mice; fullerenol, $10^{6} \mathrm{GFP}$-expressing adipose-derived stem cells and $100 \mathrm{mg} / \mathrm{kg}$ fullerenol treated group.

adipose differentiation of ADSC in model group, compared with the fullerennol group $(\mathrm{P}<0.05$; Fig. 1$)$. As presented in Fig. 1, fullerenol induced adipose differentiation of ADSC significantly when compared with the control group $(\mathrm{P}<0.05)$.

Effect of fullerenol on the retention rate of D-galactose-induced mice. The retention rate of the $\mathrm{D}$-galactose model group was lower than that of control group. ADSCs and $100 \mathrm{mg} / \mathrm{kg}$ fullerenol markedly increased the D-galactose-inhibition of retention rate in mice (Fig. 2).

Effect of fullerenol on the thickness of the dermal portion of skin and collagen ratio. Following fullerenol treatment, the thickness of the dermal portion of skin and collagen ratio was significantly decreased compared with the control group rats $(\mathrm{P}<0.05$; Fig. 3). As presented in Fig. 3, treatment with fullerenol significantly promoted D-galactose-inhibition of the thickness of the dermal portion of skin and collagen ratio mice.

Effect of fullerenol on cytotoxicity and cell viability of $D$-galactose-induced mice. The anti-aging effect of fullerenol on the cytotoxicity (Fig. 4A) and cell viability (Fig. 4B) of D-galactose-induced mice was identified and Fig. 4 indicates the cytotoxicity and cell viability rates for all groups treated with $0.1,0.3,1$ or $3 \mu \mathrm{M}$ fullerenol. No significant difference was observed between groups ( $\mathrm{P}>0.05$; Fig. 4).

Effect of fullerenol on Runx2 of D-galactose-induced mice. To investigate the anti-aging effect of fullerenol on Runx 2 of D-galactose-induced mice, the expression of the Runx2 gene was detected using RT-qPCR. As presented in Fig. 5, Runx2 gene expression in the $\mathrm{D}$-galactose-induced model group was significantly lower than that of control mice $(\mathrm{P}<0.05)$. Treatment with fullerenol was effective in significantly 

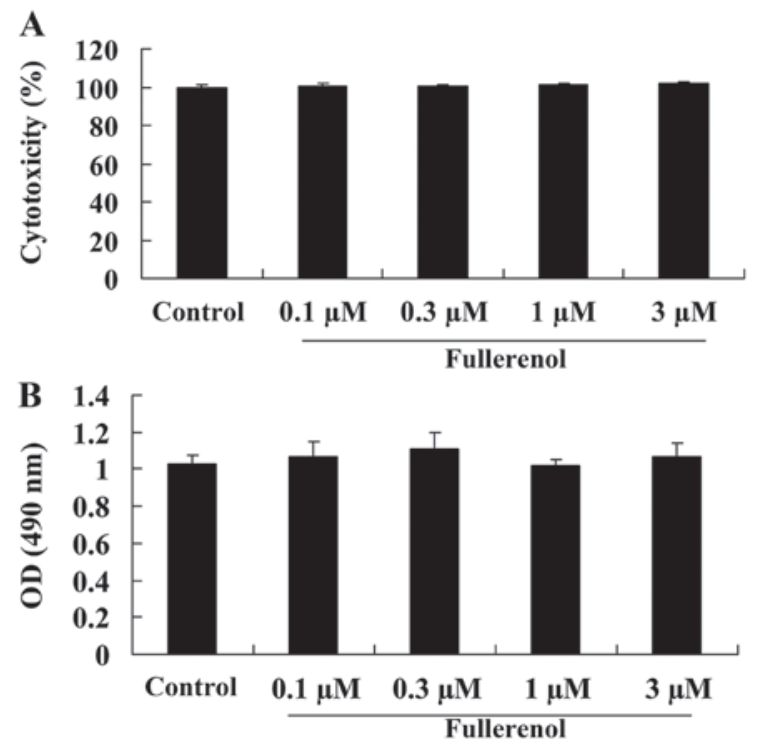

Figure 4. Effect of fullerenol on the cytotoxicity and cell viability of D-galactose-induced mice. Anti-aging effect of fullerenol on (A) cytotoxicity and (B) cell viability of D-galactose-induced mice following treatment with $0.1,0.3,1$ and $3 \mu \mathrm{M}$ fullerenol for $24 \mathrm{~h}$. Control, control group; model, D-galactose-induced model mice; fullerenol, $10^{6}$ GFP-expressing adipose-derived stem cells and $100 \mathrm{mg} / \mathrm{kg}$ fullerenol treated group; OD, optical density.

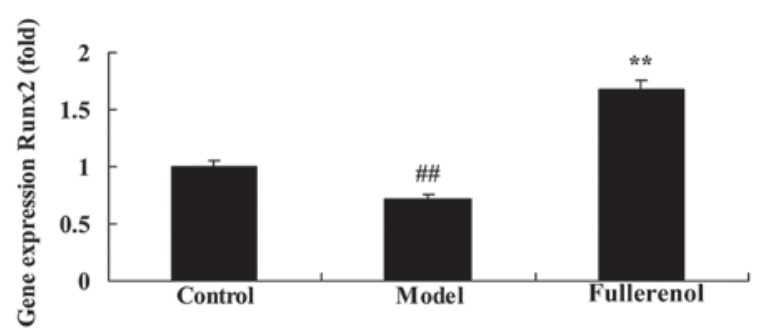

Figure 5. Effect of fullerenol on Runx2 expression in D-galactose-induced mice. ${ }^{\# \#} \mathrm{P}<0.01$ vs. control group; ${ }^{* *} \mathrm{P}<0.01$ vs. model group. Control, control group; model, D-galactose-induced model mice; fullerenol, $10^{6}$ GFP-expressing adipose-derived stem cells and $100 \mathrm{mg} / \mathrm{kg}$ fullerenol treated group; Runx2, Runt-related transcription factor 2.

decreasing the expression of Runx2 in D-galactose-induced mice $(\mathrm{P}<0.05$; Fig. 5$)$.

Effect of fullerenol on ALP of D-galactose-induced mice. In order to confirm that fullerenol has a protective anti-aging effect on skin, ALP gene expression in D-galactose-induced mice was assessed. Gene expression of ALP in D-galactose-induced mice was significantly lower than that of control mice $(\mathrm{P}<0.05$; Fig. 6$)$. Treatment with fullerenol significantly increased the expression of the ALP gene in D-galactose-induced mice ( $\mathrm{P}<0.05$; Fig. 6).

Effect of fullerenol on OCN of D-galactose-induced mice. To confirm the anti-aging effect of fullerenol on OCN in ADSCs, OCN gene expression was measured using RT-qPCR. Compared with control mice, there was a significant decrease in OCN gene expression of D-galactose-induced model mice $(\mathrm{P}<0.05$; Fig. 7). As presented in Fig. 7, fullerenol treatment

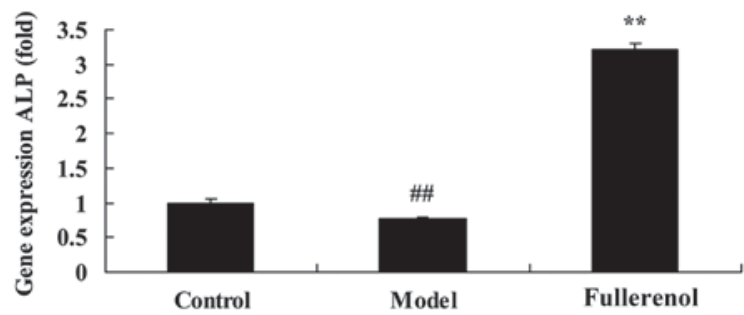

Figure 6. Effect of fullerenol on ALP expression in D-galactose-induced mice. ${ }^{\# \#} \mathrm{P}<0.01$ vs. control group; ${ }^{* *} \mathrm{P}<0.01$ vs. model group. Control, control group; model, D-galactose-induced model mice; fullerenol, $10^{6}$ GFP-expressing adipose-derived stem cells and $100 \mathrm{mg} / \mathrm{kg}$ fullerenol treated group; ALP, alkaline phosphatase.

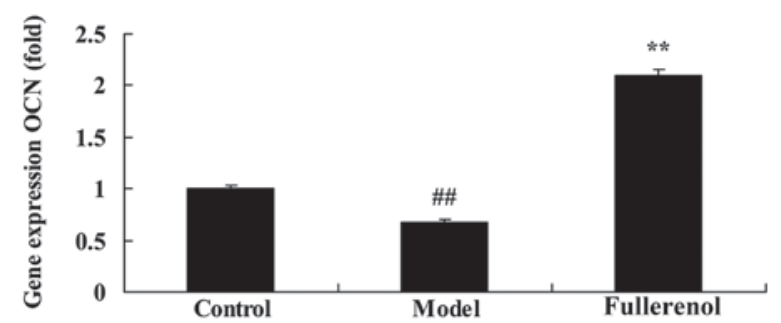

Figure 7. Effect of fullerenol on OCN expression in D-galactose-induced mice. ${ }^{\# \#} \mathrm{P}<0.01$ vs. control group; ${ }^{* *} \mathrm{P}<0.01$ vs. model group. Control, control group; model, D-galactose-induced model mice; fullerenol, $10^{6}$ GFP-expressing adipose-derived stem cells and $100 \mathrm{mg} / \mathrm{kg}$ fullerenol treated group; OCN, osteocalcin.

significantly inhibited the D-galactose-inhibition of OCN gene expression in D-galactose-induced mice compared with that of D-galactose-induced model group, leading to a significant increase in the expression of OCN ( $\mathrm{P}<0.05$; Fig. 7).

Effect of fullerenol on PPAR- $\gamma$ of D-galactose-induced mice. The anti-aging effect of fullerenol on PPAR- $\gamma$ of D-galactose-induced mice was investigated by assessing the protein expression of PPAR- $\gamma$ using western blot analysis. Western blot analysis demonstrated that PPAR- $\gamma$ protein expression in D-galactose-induced mice model group was significantly increased compared with that of the control group $(\mathrm{P}<0.05$; Fig. 8). Pretreatment with fullerenol significantly decreased the D-galactose-induced PPAR- $\gamma$ protein expression in mice, compared with mice in the D-galactose-induced model group $(\mathrm{P}<0.05$; Fig. 8).

Effect of fullerenol on FoxO 1 expression in D-galactose-induced mice. To study the potential mechanistic pathways underlying the promotion of fullerenol, FoxO1 protein expression was assessed using western blot analysis. FoxO1 protein expression in D-galactose-induced mice was significantly reduced in the model group, compared with the control group $(\mathrm{P}<0.05$; Fig. 9). However, treatment with fullerenol significantly increased D-galactose-induced inhibition of FoxO1 protein expression in mice $(\mathrm{P}<0.05$; Fig. 9).

\section{Discussion}

Skin aging is caused by endogenous and exogenous factors and is characterized by thinner and laxer skin, dry and rough skin, 
A

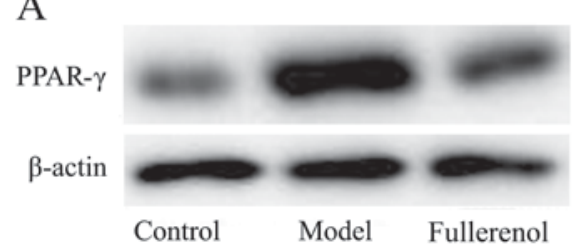

$\mathrm{B}$

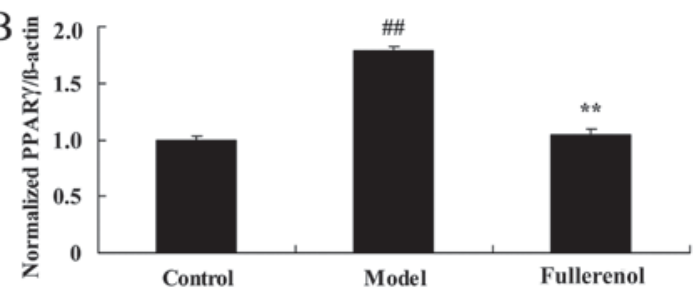

Figure 8. Effect of fullerenol on PPAR- $\gamma$ expression in D-galactose-induced mice. Anti-aging effect of fullerenol on PPAR- $\gamma$ protein expression was assessed using (A) western blot analysis and (B) statistical analysis of PPAR- $\gamma$ protein expression in D-galactose-induced mice. $\beta$-actin was used as a control. ${ }^{\#} \mathrm{P}<0.01$ vs. control group; ${ }^{* *} \mathrm{P}<0.01$ vs. model group. Control, control group; model, D-galactose-induced model mice; fullerenol, $10^{6}$ GFP-expressing adipose-derived stem cells and $100 \mathrm{mg} / \mathrm{kg}$ fullerenol treated group; PPAR- $\gamma$, peroxisome proliferator-activated receptor- $\gamma$.
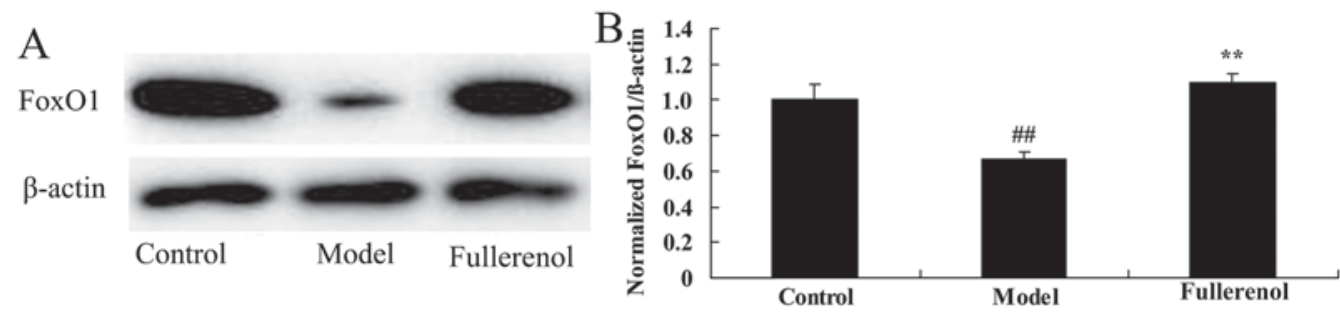

Figure 9. Effect of fullerenol on FoxO1 expression in D-galactose-induced mice. Anti-aging effect of fullerenol on FoxO1 protein expression was assessed using (A) western blot analysis and (B) statistical analysis of FoxO1 protein expression in $\mathrm{D}$-galactose-induced mice. $\beta$-actin was used as a control. ${ }^{\# \#} \mathrm{P}<0.01$ vs. control group; ${ }^{* *} \mathrm{P}<0.01$ vs. model group. Control, control group; model, D-galactose-induced model mice; fullerenol, $10^{6}$ GFP-expressing adipose-derived stem cells and $100 \mathrm{mg} / \mathrm{kg}$ fullerenol treated group; FoxO1, forkhead box protein O1.

reduced elasticity, formation of wrinkles, over-pigmentation and angiotelectasis (11). In vitro and animal experiments have demonstrated the effects of ADSCs and associated cytokines on anti-aging $(3,11)$. However, clinical studies are limited to case reports, thus the security and feasibility should be further investigated through a large numbers of clinical trials (3). In addition, in vitro expansion of stem cells may cause aging, which affects curative effects, including ameliorating inflammation and trauma (11). Under the prerequisite of anti-aging functions of cytokines secreted by ADSCs, clinical application of these cytokines is potentially more feasible (12). Consequently, following the purification of cytokines in culture medium, externally applied drugs are manufactured to increase the feasibility of ADSCs application in skin care (3). In the present study, treatment with fullerenol and ADSCs significantly increased the D-galactose-inhibition of retention rate, thickness of the dermal portion of skin and collagen ratio in D-galactose-induced mice $(\mathrm{P}<0.05)$.

Runx 2 is transcription factor in the structural domain gene family, which serves an essential role in the developmental process of bone and teeth (13). It is able to bind to specific binding sites on DNA promoter regions to regulate the transcription of target genes and participate in organ formation (14). It has been demonstrated that Runx2, as a specific transcription factor regulating the differentiation of osteoblasts, may directly induce the differentiation of mesenchymal stem cells into osteoblasts and serves an important role in adult bone tissue repair and reconstruction (5). Furthermore, the present study identified that fullerenol treatment significantly increased the Runx 2 gene expression in D-galactose-induced mice $(\mathrm{P}<0.05)$.

ALP is a phenotypic marker for osteoblasts, which may directly represent the activities and functional status of osteoblast cells (15). During early stages of osteogenesis, the activity of ALP is marked. With the increase of calcium salt deposition during the middle and late stages of osteogenic differentiation, activities of ALP gradually decrease (16). OCN is a common signal molecule that promotes osteogenesis and bone inducing factors (17). OCN is a common signal molecule to promote osteogenesis of bone inducing factors (18). Therefore, the present study identified that treatment with fullerenol significantly increased the expression of ALP and OCN in D-galactose-induced mice $(\mathrm{P}<0.05)$. Yang et al $(18)$ reported that fullerenol promotes osteogenesis of human ADSCs through Runx2, ALP and OCN.

PPAR- $\gamma$ is a subtype of peroxisome proliferator-activated receptors. Following ligand-activation, it participates in the regulation of cell differentiation, proliferation and apoptosis (19). Previous results have indicated that PPAR- $\gamma$ is a key regulation factor of adipose differentiation, which has a key regulatory role on the direction of differentiation in bone marrow stem cells (20). Both gegenbaur and fat cells in the marrow cavity originate from mesenchymal stem cells, and quantities are waxing and waning. Previous studies have demonstrated that as PPAR- $\gamma$ mediates lipid differentiation of MSCs, it may directly affect the differentiation of gegenbaur cells (21). Osteoclasts develop from hematopoietic stem cells in bone marrow, and are a primary cause of osteoporosis as they may enhance bone resorption (20). Furthermore, the present study indicated that treatment with fullerenol significantly inhibited the protein expression of PPAR $-\gamma$ in D-galactose-induced mice $(\mathrm{P}<0.05)$. Furthermore, Liu et al $(7)$ suggested that fullerenol suppresses the expression of PPAR- $\gamma$ in bone marrow stromal cells.

As a sub-type of forkhead transcription factor, FoxOs are fundamental redox sensitive transcription factors and key 
downstream effectors in phosphoinositide 3-kinase/protein kinase B pathway (22). They also controls genes regulating cell changes, including cell proliferation, survival and oxidative defense (23). It has been indicated that the decrease of FoxOs in hematopoietic stem cells may cause a decrease in antioxidase including reactive oxygen species, manganese superoxide dismutase and scavenger enzymes, resulting in dysfunction of mitochondria and cell apoptosis (24). Following a high dose of $\mathrm{H}_{2} \mathrm{O}_{2}$ applied to bone marrow mesenchymal stem cells, the expression of FoxO1, FoxO3 and FoxO4 mRNA significantly decreases (25). The present study used treatment with fullerenol and observed a significant increase in the D-galactose-induced inhibition of FoxO1 protein expression in mice. Yang et al (18) reported that fullerenol promotes osteogenesis of human ADSCs through promotion of FOXO4.

In conclusion, the results of the present study provide preliminary evidence that the anti-aging effect of fullerenol is able to enhance the D-galactose-inhibition of retention rate, thickness of the dermal portion of skin and collagen ratio in D-galactose-induced mice. This is completed by ADSC-modulation of the PPAR- $\gamma /$ FoxO1 pathway in D-galactose-induced mice. The results of the present study indicate that fullerenol may be a potential novel drug to treat skin aging. Future studies should use clinical samples to confirm that these findings have potential clinical applications.

\section{References}

1. Senbel AM, AbdelMoneim L and Omar AG: Celecoxib modulates nitric oxide and reactive oxygen species in kidney ischemia/reperfusion injury and rat aorta model of hypoxia/reoxygenation. Vascul Pharmacol 62: 24-31, 2014.

2. Weng TI, Wu HY, Chen BL and Liu SH: Honokiol attenuates the severity of acute pancreatitis and associated lung injury via acceleration of acinar cell apoptosis. Shock 37: 478-484, 2012.

3. Ishikawa C, Arbiser JL and Mori N: Honokiol induces cell cycle arrest and apoptosis via inhibition of survival signals in adult T-cell leukemia. Biochim Biophys Acta 1820: 879-887, 2012.

4. Clark RA, Weragoda N, Paterson K, Telianidis S and Williams G: A pilot investigation using global positioning systems into the outdoor activity of people with severe traumatic brain injury. J Neuroeng Rehabil 11: 37, 2014.

5. Erden A, Idilman R, Erden I and Ozden A: Veins around the esophagus and the stomach: Do their calibrations provide a diagnostic clue for portal hypertensive gastropathy? Clin Imaging 33: 22-24, 2009.

6. Injac R, Prijatelj M and Strukelj B: Fullerenol nanoparticles: Toxicity and antioxidant activity. Methods Mol Biol 1028: 75-100, 2013.

7. Liu Q, Jin L, Shen FH, Balian G and Li XJ: Fullerol nanoparticles suppress inflammatory response and adipogenesis of vertebra bone marrow stromal cells-a potential novel treatment for intervertebral disc degeneration. Spine J 13: 1571-1580, 2013.

8. Liu JM, Lin LP, Jiang SL, Cui ML, Jiao L, Zhang XY, Zhang LH, Zheng ZY, Lin X and Lin SQ: Fullerol-fluorescein isothiocyanate-concanavalin agglutinin phosphorescent sensor for the detection of alpha-fetoprotein and forecast of human diseases. Spectrochim Acta A Mol Biomol Spectrosc 115: 136-144, 2013.
9. Li Q, Mahendra S, Lyon DY, Brunet L, Liga MV, Li D and Alvarez PJ: Antimicrobial nanomaterials for water disinfection and microbial control: Potential applications and implications. Water Res 42: 4591-4602, 2008.

10. Kakutani H, Hino S, Ikeda K, Sumiyama K, Uchiyama Y, Kuramochi A, Kawamura M and Tajiri H: Prediction of recurrence of esophageal varices-special reference to a role for endoscopic ultrasonography. Hepatol Res 33: 259-266, 2005.

11. Marmulla R and Harder J: Microbial monoterpene transformations-a review. Front Microbiol 5: 346, 2014.

12. Chen YJ, Tsai KS, Chan DC, Lan KC, Chen CF, Yang RS and Liu SH: Honokiol, a low molecular weight natural product, prevents inflammatory response and cartilage matrix degradation in human osteoarthritis chondrocytes. J Orthop Res 32: 573-580, 2014.

13. Chiang J, Shen YC, Wang YH, Hou YC, Chen CC, Liao JF, Yu MC, Juan CW and Liou KT: Honokiol protects rats against eccentric exercise-induced skeletal muscle damage by inhibiting NF-kappaB induced oxidative stress and inflammation. Eur J Pharmacol 610: 119-127, 2009.

14. Huang LY, Zhang B, Cui J, Liu YX, Wu CR and Lin SJ: Sequential therapy for patients with cirrhosis complicated by common bile duct stones and moderate to severe gastroesophageal varices. Chin Med J (Engl) 125: 4312-4314, 2012.

15. Lo EA, Wilby KJ and Ensom MH: Use of proton pump inhibitors in the management of gastroesophageal varices: A systematic review. Ann Pharmacother 49: 207-219, 2015.

16. Harrison-Felix C, Kreider SE, Arango-Lasprilla JC, Brown AW, Dijkers MP, Hammond FM, Kolakowsky-Hayner SA, Hirshson C, Whiteneck G and Zasler ND: Life expectancy following rehabilitation: A NIDRR traumatic brain injury model systems study. J Head Trauma Rehabil 27: E69-E80, 2012.

17. Zafonte RD, Bagiella E, Ansel BM, Novack TA, Friedewald WT, Hesdorffer DC, Timmons SD, Jallo J, Eisenberg H, Hart T, et al: Effect of citicoline on functional and cognitive status among patients with traumatic brain injury: Citicoline Brain Injury Treatment Trial (COBRIT). JAMA 308: 1993-2000, 2012.

18. Yang X, Li CJ, Wan Y, Smith P, Shang G and Cui Q: Antioxidative fullerol promotes osteogenesis of human adipose-derived stem cells. Int J Nanomedicine 9: 4023-4031, 2014.

19. Soontornniyomkij V, Choi C, Pomakian J and Vinters HV: High-definition characterization of cerebral $\beta$-amyloid angiopathy in Alzheimer's disease. Hum Pathol 41: 1601-1608, 2010.

20. Roh JH, Huang Y, Bero AW, Kasten T, Stewart FR, Bateman RJ and Holtzman DM: Disruption of the sleep-wake cycle and diurnal fluctuation of $\beta$-amyloid in mice with Alzheimer's disease pathology. Sci Transl Med 4: 150ra122, 2012. doi: 10.1126/scitranslmed.3004291.

21. Yuan F, Xu ZM, Lu LY, Nie H, Ding J, Ying WH and Tian HL: SIRT2 inhibition exacerbates neuroinflammation and blood-brain barrier disruption in experimental traumatic brain injury by enhancing NF- $\kappa \mathrm{B}$ p65 acetylation and activation. J Neurochem 136: 581-593, 2016.

22. Turkstra LS, Quinn-Padron M, Johnson JE, Workinger MS and Antoniotti N: In-person versus telehealth assessment of discourse ability in adults with traumatic brain injury. J Head Trauma Rehabil 27: 424-432, 2012.

23. Stein TD, Montenigro PH, Alvarez VE, Xia W, Crary JF, Tripodis Y, Daneshvar DH, Mez J, Solomon T, Meng G, et al: Beta-amyloid deposition in chronic traumatic encephalopathy. Acta Neuropathol 130: 21-34, 2015.

24. Kalinin S, Gavrilyuk V, Polak PE, Vasser R, Zhao J, Heneka MT and Feinstein DL: Noradrenaline deficiency in brain increases beta-amyloid plaque burden in an animal model of Alzheimer's disease. Neurobiol Aging 28: 1206-1214, 2007.

25. Zwan MD, Okamura N, Fodero-Tavoletti MT, Furumoto S, Masters CL, Rowe CC and Villemagne VL: Voyage au bout de la nuit: $A \beta$ and tau imaging in dementias. Q J Nucl Med Mol Imaging 58: 398-412, 2014. 